\title{
Synthesis of PMMA-b-PU-b-PMMA tri-block copolymers through ARGET ATRP in the presence of air
}

\author{
P. Król ${ }^{*}$, P. Chmielarz \\ Department of Polymer Science, Faculty of Chemistry, Rzeszów University of Technology, Al. Powstańców Warszawy 6 , \\ 35-959 Rzeszów, Poland
}

Received 11 September 2012; accepted in revised form 10 November 2012

\begin{abstract}
ARGET (activators regenerated by electron transfer) ATRP (atom transfer radical polymerization) has been successfully performed (in flasks fitted with rubber septa without the need for use of Schlenk line) in the presence of limited amount of air and with a very small $(370 \mathrm{ppm})$ amount of copper catalyst together with an appropriate reducing agent $\mathrm{Cu}(0)$. Novelty of this work is that the poly(methyl methacrylate)-block-polyurethane-block-poly(methyl methacrylate) triblock copolymers were synthesized for the first time through ARGET ATRP, by using tertiary bromine-terminated polyurethane as a macroinitiator (MBP-PU-MBP), $\mathrm{CuBr}_{2}$ or $\mathrm{CuCl}_{2}$ as a catalyst and $N, N, N^{\prime}, N^{\prime \prime}, N^{\prime \prime}$-pentamethyldiethylenetriamine (PMDETA) or 2,2'-bipyridine (Bpy) as a complexing agent. As the polymerization time increases, both the monomer conversion and $\ln \left([\mathrm{M}]_{0} /[\mathrm{M}]\right)$ increased and the molecular weight of copolymer increases linearly with increasing conversion. Theoretical number-average molecular weight $\left(M_{\mathrm{n}, \text { th }}\right)$ of the tri-block copolymers was found to be comparable with number-average molecular weight determined by GPC analyses $\left(M_{\mathrm{n}, \mathrm{GPC}}\right)$. These results indicate that the formation of the tri-block copolymers was through atom transfer radical polymerization mechanism. ${ }^{1} \mathrm{H}$ and ${ }^{13} \mathrm{C}$ NMR spectral methods were employed to confirm chemical structures of synthesized macroinitiator and tri-block copolymers. Mole percentage of PMMA in the tri-block copolymers was calculated using ${ }^{1} \mathrm{H}$ NMR spectroscopy and was found to be comparable with the GPC results. Additionally, the studies of surface properties (confocal microscopy and SFE) of tri-block copolymer coatings confirmed the presence of MMA segments.
\end{abstract}

Keywords: polymer synthesis, molecular engineering, ATRP, ARGET ATRP, brominated polyurethanes

\section{Introduction}

Atom transfer radical polymerization (ATRP) is one of the most rapidly developing areas of polymer science, allowing to obtain effective control over molecular weights, narrow molecular weight distributions, architectures, and well-defined compositions. However, normal ATRP has one notable limitation that is the catalyst used is sensitive to air and other oxidants. In order to overcome this drawback, Matyjaszewski's group has developed ATRP technique, namely activator regenerated by electron transfer atom transfer radical polymerization (ARGET ATRP) [1]. This method provides a continuous con- trolled polymerization with a significant reduction of the amount of copper-based catalyst complex $(<50 \mathrm{ppm})$ due to a constant regeneration of the $\mathrm{Cu}(\mathrm{I})$ activator species by reducing agents, which compensate for any loss of $\mathrm{Cu}(\mathrm{I})$ by termination [2]. ARGET ATRP was successfully applied to relatively nonpolar monomers (e.g., styrene, butyl acrylate, and methyl methacrylate) [3], for the preparation of polymeric materials with different structures and architectures including homopolymers, block copolymers, and development of a scalable process for preparation of molecular brushes on a flat surface [1]. However, tri-block copolymers have sparked

\footnotetext{
${ }^{*}$ Corresponding author, e-mail: pkrol@prz.edu.pl

(C) BME-PT
} 
much interest and their potential has been realized in many areas (membranes, biodegradable polymers). Block copolymers are an interesting class of materials that possess different properties compared to those of each individual homopolymer segments they are composed of. As block length is playing a major role on the properties of the block copolymers, effective control of the block lengths is important and this can easily be achieved using different controlled radical polymerization (CRP) methods [4].

Polyurethanes (PUs) are of commercial interest due to their excellent properties such as high chemical resistance and high strength. The physical and chemical properties of polyurethane (PU) depend on the type and composition of polyol, diisocyanate, the chain extender, and other additives. Conventional PU is hydrophobic in nature, but when ionic groups are incorporated, PU with both hydrophobic and hydrophilic segments is obtained, which, in turn, forms dispersion when water is added [5]. Meanwhile, in the present investigation, we focused on the synthesis of moderately hydrophobic PU macroinitiator modified by incorporating methyl methacrylate (MMA) as hydrophobic monomer in order to obtain copolymers with increased hydrophobicity.

Tri-block copolymers with using different polyurethane based macroinitiators were already obtained through ATRP classical mechanism [6, 7]. However, this method was arduous because of the degassing of the reaction mixture, therefore in the current study we used ARGET ATRP, with the aim of omitting the deoxygenation process. Although the chemical basis of polymerization ATRP has been known for about 5 years, this technique has not yet been used for the synthesis of tri-block copolymers using $\mathrm{PU}$ as a macroinitiator. In the present investigation, we focused on ARGET ATRP of MMA in the presence of tertiary bromine-terminated $\left(-\mathrm{C}\left(\mathrm{CH}_{3}\right)_{2} \mathrm{Br}\right)$ polyurethane (MBP-PU-MBP) as a macroinitiator, $\mathrm{CuBr}_{2}$ and $\mathrm{CuCl}_{2}$ as a catalyst, $N, N, N^{\prime}, N^{\prime \prime}, N^{\prime \prime}$-pentamethyldiethylenetriamine (PMDETA) and 2,2'bipyridine (Bpy) as a complexing agent. In this article, we report that ARGET ATRP can be successfully carried out in the presence of limited amounts

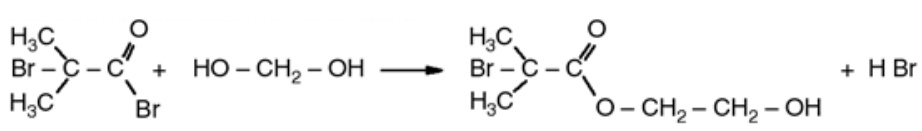

Figure 1. Synthesis of HMB initiator of air and control is essentially unaffected by excess reducing agent. Reactions can be carried out without any deoxygenation, in flasks fitted with rubber septa. It is important here to mention that the resulting poly(methyl methacrylate)-block-polyurethaneblock-poly(methyl methacrylate) (PMMA- $b$-PU- $b$ PMMA) tri-block copolymers obtained through ARGET ATRP is reported now for the first time.

\section{Experimental section}

\subsection{Materials}

4,4'-Methylene diphenyl diisocyanate (MDI), dibutyltin dilaurate (DBTDL), $\alpha$-bromoisobutyryl bromide (BB; 98\%), ethylene glycol (99.9\%) and copper $(0)$ metal turnings $(\geq 99 \%)$ were used as received from Sigma-Aldrich Inc., St. Louis, USA. Polyoxytetramethylene glycol of molecular weight 1000 (PTMG; Merck, Darmstadt, Germany) was purified by heating at $105^{\circ} \mathrm{C}$ under vacuum for $3 \mathrm{~h}$ before use. Methyl methacrylate (MMA; 99\%; Sigma-Aldrich, USA), $\mathrm{CuBr}_{2}$ (99\%; Sigma-Aldrich, USA), $\mathrm{CuCl}_{2}$ (97\%; Sigma-Aldrich, USA), Bpy ( $\geq 99 \%$; Sigma-Aldrich, USA) and PMDETA ( $\geq 98 \%$; Merck, Germany) were used without further purification. Sodium carbonate (99.5\%), magnesium sulfate $(98.5 \%)$, dichloromethane $(99.5 \%)$, acetonitrile (99.5\%), methanol (99.9\%) and acetone (99.5\%) were obtained from Chempur, Piekary Śląskie, Poland. Analytical grade $N, N$-dimethylformamide (DMF; Chempur, Poland) and methyl ethyl ketone (MEK; Chempur, Poland), were distilled and the middle portions were used after storing over type 4 Å molecular sieves.

\subsection{Synthesis of 2-hydroxyethyl-2'-methyl-2'- bromopropionate (HMB)}

HMB (ATRP initiator) was synthesized according to Figure 1.

Bromoisobutyryl bromide was reacted with cold anhydrous ethylene glycol (excess) under stirring for $4 \mathrm{~h}$. The molar ratio of ethylene glycol and $a$-bromoisobutyryl bromide was 25 in order to avoid coupling reaction. The reaction mixture was added to deionized water, and the reaction product was extracted by dichloromethane. The organic solution 
was washed with water and sodium carbonate and dried over anhydrous magnesium sulfate. The final product was isolated as a liquid upon removal of the solvent (yield $88 \%$ ) and stored at $0-4^{\circ} \mathrm{C}$ until use [8].

\subsection{Synthesis of tertiary bromine-terminated polyurethane (MBP-PU-MBP)}

2-methyl-2-bromopropionate terminated polyurethane macroinitiator was synthesized from one mole of PTMG, two moles of MDI, and two moles of HMB (Figure 2).

First stage includes synthesis of prepolymer from MDI (7.5 g, $0.03 \mathrm{~mol})$ and PTMG (15 g, $0.015 \mathrm{~mol})$ in $40 \mathrm{~mL}$ MEK at $40^{\circ} \mathrm{C}$ in a atmosphere of nitrogen for $1 \mathrm{~h}$. The temperature was then raised to $65^{\circ} \mathrm{C}$ for $2 \mathrm{~h}$ and the reaction was allowed to proceed till the isocyanate content reached half the initial value (2,31\% content of $-\mathrm{NCO}$ groups in the prepolymer about $M_{\mathrm{n}}=6960 \mathrm{~g} / \mathrm{mol}$, as determined by dibutyl amine titration).

In the second stage, prepolymer was end-capped by addition of HMB ( $6.33 \mathrm{~g}, 0.03 \mathrm{~mol})$ in the presence of MEK $(20 \mathrm{~mL})$. Then $0.03 \mathrm{~g}$ of DBTDL catalyst was added, the temperature was raised to $70^{\circ} \mathrm{C}$ and the reaction was allowed to go to completion as confirmed $0 \%$ content of $-\mathrm{NCO}$ groups and the disappearance of isocyanate peak by FT-IR (Figure 4). The resulting macroinitiator solution was dried at $70^{\circ} \mathrm{C}$ in vacuum and stored at $0-4^{\circ} \mathrm{C}$ until use. Recently, similar method was also used to synthe- size polyurethane macroinitiator from PTMG, toluene diisocyanate (TDI) and HMB [6].

\subsection{ARGET ATRP of MMA using MBP-PU-MBP/CuX $\mathbf{X}_{2} /$ Ligand initiating system}

Synthesis of the tri-block copolymers were conducted in $100^{\circ} \mathrm{C}$ for $30 \mathrm{~h}$. PMMA- $b$-PU- $b$-PMMA were synthesized using polyurethane macroinitiator, reducing agent $\mathrm{Cu}(0)$, copper catalyst $\mathrm{CuX}_{2}$ $\left(\mathrm{CuBr}_{2}, \mathrm{CuCl}_{2}\right)$ and PMDETA or Bpy as a ligand (Figure 3). A typical example of the general procedure in the presence of air was as follows.

A solution of catalyst was made by dissolving copper catalyst $\mathrm{CuBr}_{2}(3.57 \mathrm{mg}, 0.016 \mathrm{mmol})$ or $\mathrm{CuCl}_{2}$ $(2.15 \mathrm{mg}, 0.016 \mathrm{mmol})$ and ligand PMDETA $(11.09 \mathrm{mg}, \quad 0.064 \mathrm{mmol})$ or Bpy $(9.99 \mathrm{mg}$, $0.064 \mathrm{mmol})$ in DMF $(1.4 \mathrm{~mL})$. Then $13 \mathrm{~mL}$ glass vial containing a solution of catalyst was charged with MBP-PU-MBP (0.97 g, $0.16 \mathrm{mmol})$ dissolved in DMF (2 mL) and MMA (3.204 g, $32 \mathrm{mmol}$ ), after which metallic copper was added $(81.3 \mathrm{mg}$, $1.28 \mathrm{mmol}$ ) to initiate polymerization. Next the system was partially deoxygenated by bubbling $\mathrm{N}_{2}$ for two minutes, after which the initial sample was taken. The sealed vial with a plastic screw cap was placed in an oil bath thermostated at $100^{\circ} \mathrm{C}$. For all 4 synthesis catalyst concentration was $370 \mathrm{ppm}$ with respect to final polymer. Samples were taken at timed intervals and analyzed by GPC and NMR to

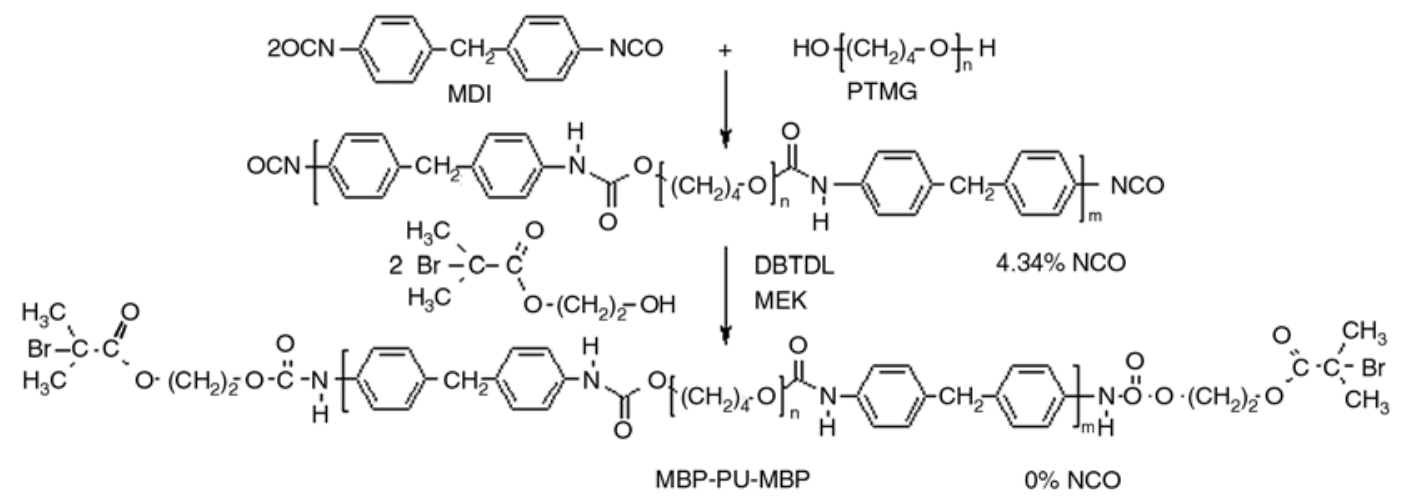

Figure 2. Synthesis of MBP-PU-MBP

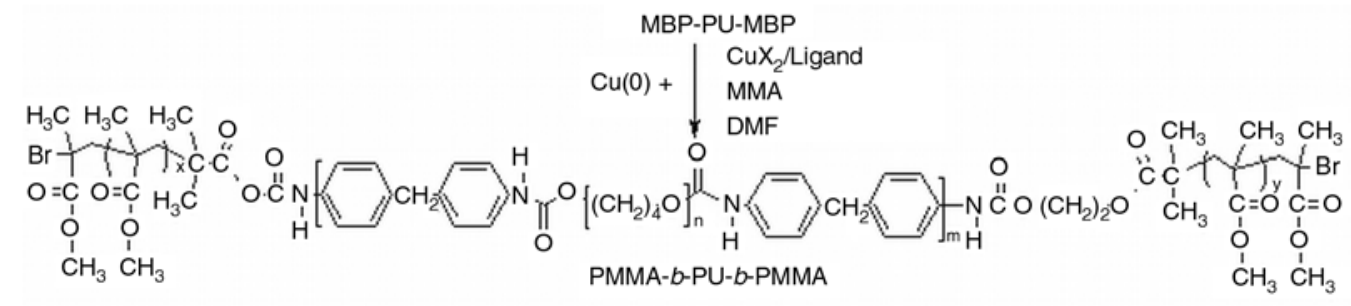

Figure 3. Synthesis of PMMA- $b$-PU- $b$-PMMA tri-block copolymers through ARGET ATRP 
follow the progress of the reaction. The polymerization was stopped after $30 \mathrm{~h}$ by opening the vial and exposing the catalyst to air. The resulting solution was poured with methanol and acetonitrile. Resulting pure copolymers were dried at $70^{\circ} \mathrm{C}$ under vacuum.

\subsection{Characterization techniques}

FT-IR spectra were taken with the spectrophotometer Nicolet 6700 FT-IR (Thermo Scientific, Madison, USA), within $4000-500 \mathrm{~cm}^{-1}$, with the use of attenuated total reflectance (ATR) technique (the polymer film was placed between prism walls).

Number-average $\left(M_{\mathrm{n}}\right)$ and weight-average $\left(M_{\mathrm{w}}\right)$ molecular weights and molecular weight distribution (MWD) were determined by GPC using a Viscotek T60A system (Viscotek, Houston, USA) equipped with a triple detector: refractometric (RI), light scattering (LS) and viscosity detector (DV). Separations were made at $25 \pm 0.1^{\circ} \mathrm{C}$ on a GMHHRL column packed with TSK-gel of pore diameter $5 \mu \mathrm{m}$ Thoso-Haas, and Styragel 1 and 2 Waters. The THF flow rate was $1 \mathrm{~mL} / \mathrm{min}$. Operation of the chromatograph was controlled by original computer software TRISEC Data Acquisition System by Viscotec Corporation.

${ }^{1} \mathrm{H}$ and ${ }^{13} \mathrm{C}$ NMR spectra were taken with the use of the spectrometer FT-NMR Bruker Avance 500 II (Bruker, Karlsruhe, Germany). The sample of HMB was dissolved in $\mathrm{CDCl}_{3}$, while samples of macroinitiator and copolymers were dissolved in DMSO$d_{6} / h$-DMSO and the solutions with the concentration of about $0.2 \mathrm{~g} / \mathrm{dm}^{3}$ were prepared. TMS was used as a standard.

Monomer conversion $(\alpha)$ was calculated from the ${ }^{1} \mathrm{H}$ NMR spectra of the copolymer samples Equation (1) by comparison of the integration for methine proton of the MMA ( $\delta=5.68-6.03 \mathrm{ppm})$ [9], with the signals from aromatic protons of the macroinitiator $(\delta=7.08-7.39 \mathrm{ppm})$ :

$\alpha=100 \%-\left[\begin{array}{l}\frac{I_{\mathrm{q}, \mathrm{n}}+I_{\mathrm{q}^{\prime}, \mathrm{n}}}{I_{\mathrm{l}, \mathrm{n}}+I_{\mathrm{k}, \mathrm{n}}} \\ \frac{I_{\mathrm{q}, 0}+I_{\mathrm{q}^{\prime}, 0}}{I_{\mathrm{l}, 0}+I_{\mathrm{k}, 0}}\end{array} 100 \%\right]$

where $I_{\mathrm{q}, 0}$ and $I_{\mathrm{q}^{\prime}, 0}$ denotes the initial integration of the methine proton of the MMA, $I_{\mathrm{q}, \mathrm{n}}$ and $I_{\mathrm{q}^{\prime}, \mathrm{n}}$ - integration of the methine proton of the MMA after time $t=3,6,12,18,24,30 \mathrm{~h}, I_{1,0}$ and $I_{\mathrm{k}, 0}-$ initial integration of the aromatic protons of the MBP-PU-
MBP, $I_{1, \mathrm{n}}$ and $I_{\mathrm{k}, \mathrm{n}}$ - initial integration of the aromatic protons of the MBP-PU-MBP after time $t=3$, $6,12,18,24,30 \mathrm{~h}$.

Based on the previous research [5], the theoretical molecular weight, $M_{\mathrm{n} \text {, th }}$ of the synthesized copolymer could be calculated by Equation (2):

$M_{\mathrm{n}, \mathrm{th}}=\left[\left(\frac{[\mathrm{M}]_{0}}{[\mathrm{I}]_{0}}\right) \cdot \alpha \cdot M_{\mathrm{M}}\right]+M_{\mathrm{I}}$

where $[\mathrm{M}]_{0}$ denotes the initial concentration of the MMA, $[\mathrm{I}]_{0}$ - initial concentration of the MBP-PUMBP, $M_{\mathrm{M}}-$ molecular weight of the MMA, $M_{\mathrm{I}}-$ molecular weight of the MBP-PU-MBP (determined by GPC analyses) and $\alpha$ - monomer conversion (1).

Molar content of PMMA $\left(\beta_{\mathrm{NMR}}\right)[6,7]$ was calculated from the ${ }^{1} \mathrm{H}$ NMR spectra of the copolymer samples using Eqution (3), by comparing $M_{\mathrm{n} \text {,th }}$ values of MBP-PU-MBP and PMMA- $b$-PU- $b$-PMMA:

$\beta_{\mathrm{NMR}}=\left(\frac{M_{\mathrm{n}, \mathrm{th}, \mathrm{n}}-M_{\mathrm{I}}}{M_{\mathrm{I}}}\right) \cdot 100$

where $M_{\mathrm{n}, \text { th,n }}$ denotes the $M_{\mathrm{n}, \mathrm{th}}$ of the PMMA- $b$-PU$b$-PMMA after time $t=3,6,12,18,24,30 \mathrm{~h}$, calculated by Equation (2), $M_{\mathrm{I}}-M_{\mathrm{n} \text {,th }}$ of the MBP-PUMBP (determined by ${ }^{1} \mathrm{H}$ NMR analyses).

Also it can easily be found out by comparing $M_{\mathrm{n}, \mathrm{GPC}}$ of MBP-PU-MBP and PMMA- $b$-PU- $b$-PMMA copolymers $\left(\beta_{\mathrm{GPC}}\right)[6,7]$, by Equation (4):

$\beta_{\mathrm{GPC}}=\left(\frac{M_{\mathrm{n}, \mathrm{GPC}, \mathrm{n}}-M_{\mathrm{I}}}{M_{\mathrm{I}}}\right) \cdot 100$

where $M_{\mathrm{n}, \mathrm{GPC}, \mathrm{n}}$ denotes the $M_{\mathrm{n}, \mathrm{GPC}}$ of the PMMA- $b$ PU- $b$-PMMA after time $t=3,6,12,18,24,30 \mathrm{~h}, M_{\mathrm{I}}$ $-M_{\mathrm{n}}$ of the MBP-PU-MBP (determined by GPC analyses).

Thermal gravimetric analysis of the obtained MBPPU-MBP and PMMA- $b$-PU- $b$-PMMA copolymers involved the use of a TGA/DSC1 thermobalance from Mettler Toledo (Warsaw, Poland). TG; $\Delta m / m=$ $f(T)$ and DTG; $\mathrm{d} m / \mathrm{d} T=f(T)$ were derived. The measurements were taken within the temperature range of $25-600^{\circ} \mathrm{C}$, at a constant heating rate of $10^{\circ} / \mathrm{min}$, in nitrogen.

The tri-block copolymers coating for studies of surface properties were formed by applying the PMMA$b$-PU-b-PMMA dissolved in acetone to a surface of silicon base and evaporation of water by air-drying at $25^{\circ} \mathrm{C}$. The coatings were then subjected to seasoning under such conditions over 10 days. 
Confocal microscopy analyses were taken with the optical 3D NanoFocus system (Oberhausen, Germany) using objectives $320 \times 320 \mu \mathrm{m}$ and magnification $50 \times$. Values of the coefficients of roughness $R_{\mathrm{a}}$ (arithmetic mean deviation of the assessed profile) and $R_{\mathrm{Z}}$ (maximum height of the profile within a sampling length) were obtained from the $\mu$ surf Premium software.

As in our previous work [10] also here, the physical parameters of surface energy of a solid $\gamma_{\mathrm{S}}$ were found on the basis of the van-Oss-Good model. The contact angles $\Theta$ were measured with the use of Cobrabid Optica goniometer (Warsaw, Poland). Values of $\Theta$ obtained from the software Kropla were used to calculate by software Energia values of $\gamma_{\mathrm{S}}$ copolymer coatings.

\section{Results and discussion}

HMB was widely used to synthesize ATRP initiators, which were used to synthesize homopolymers (e.g. poly(methyl acrylate) [11]) and block copolymers (e.g. polystyrene-g-poly(methyl methacrylate) copolymer [12]) with desired functionality and composition.

As block copolymers with narrow MWD could not be achieved using our previously reported $-\mathrm{CH}_{2} \mathrm{Br}$ terminated PU macroinitiator (and $M_{\mathrm{n} \text {,th }}$ values of the tri-block copolymers were not matching with $M_{\mathrm{n}, \mathrm{GPC}}$ values) [13], we decided to prepare $\mathrm{C}\left(\mathrm{CH}_{3}\right)_{2} \mathrm{Br}$ terminated $\mathrm{PU}$ macroinitiator and used as an ATRP initiator to synthesize hydrophobic poly(methyl methacrylate)- $b$-polyurethane- $b$-poly (methyl methacrylate) block copolymers with narrow MWD. It is expect, that the tertiary radical $\dot{\mathrm{C}}\left(\mathrm{CH}_{3}\right)_{2}$, can be generated from $-\mathrm{C}\left(\mathrm{CH}_{3}\right)_{2} \mathrm{Br}$ terminated $\mathrm{PU}$ which is more stable than the $\dot{\mathrm{C}} \mathrm{H}_{2}$ radical from $-\mathrm{CH}_{2} \mathrm{Br}$ terminated $\mathrm{PU}$ [7].
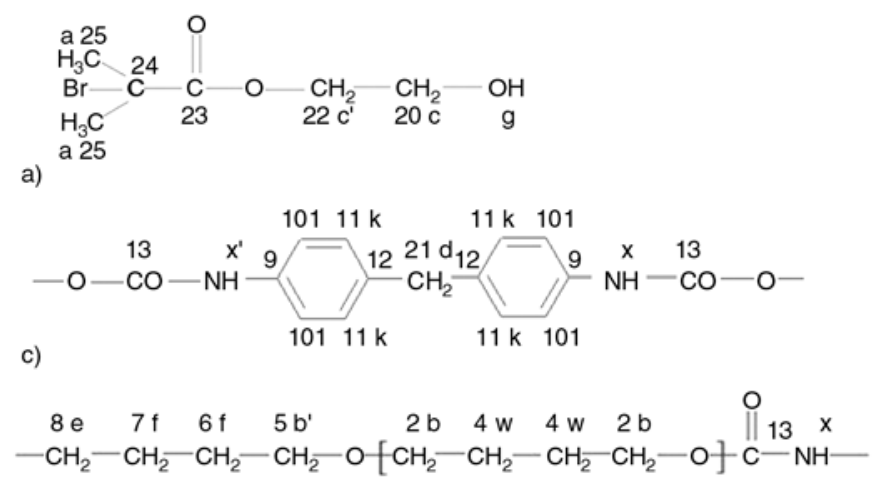

d)

\subsection{Chemical structure of ATRP initiator, MBP-PU-MBP and copolymers}

Figure 4 shows the FT-IR spectra of polyurethanebased macroinitiator MBP-PU-MBP.

In the FT-IR spectrum of MBP-PU-MBP (Figure 4) there is no presence the band at $2272 \mathrm{~cm}^{-1}$ which represent asymmetrical stretching vibrations of $-\mathrm{NCO}$ groups (specific for isocyanates). The lack of this band is confirming that the macroinitiator was end-capped by bromine.

The chemical structures of the synthesized HMB, MBP-PU-MBP and PMMA- $b$-PU- $b$-PMMA triblock copolymer (CM4BrP6 sample) shown in Figure 5 were confirmed by ${ }^{1} \mathrm{H}$ NMR and ${ }^{13} \mathrm{C}$ NMR spectroscopy (Table 1 and 2). Moreover, in the ${ }^{1} \mathrm{H}$ NMR spectrum of MBP-PU-MBP the characteristic signal of the NH proton derived from allophanates is not observed at $10.65 \mathrm{ppm}$, as well as in the ${ }^{13} \mathrm{C}$ NMR spectrum of MBP-PU-MBP the characteristic signal of the $\mathrm{C}=\mathrm{O}$ group from allophanates is not observed at about 151 and $155 \mathrm{ppm}$ [14].

These results of ${ }^{1} \mathrm{H}$ NMR and ${ }^{13} \mathrm{C}$ NMR spectroscopy show that HMB, MBP-PU-MBP and CM4BrP6 copolymer were successfully synthesized.

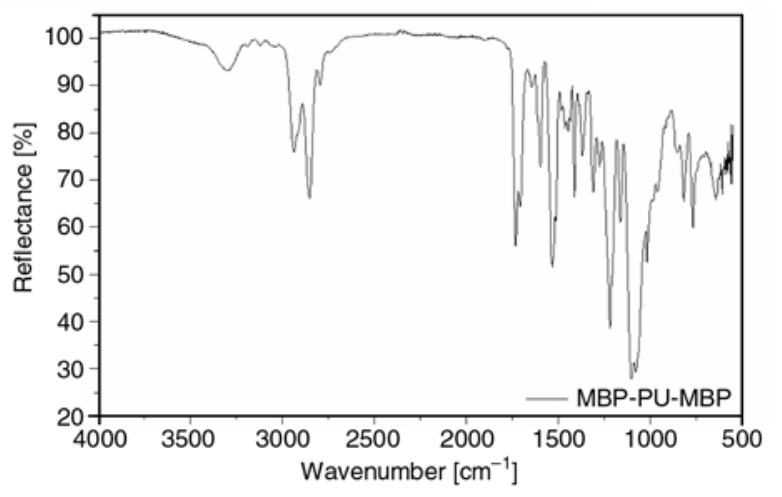

Figure 4. FT-IR spectra of MBP-PU-MBP
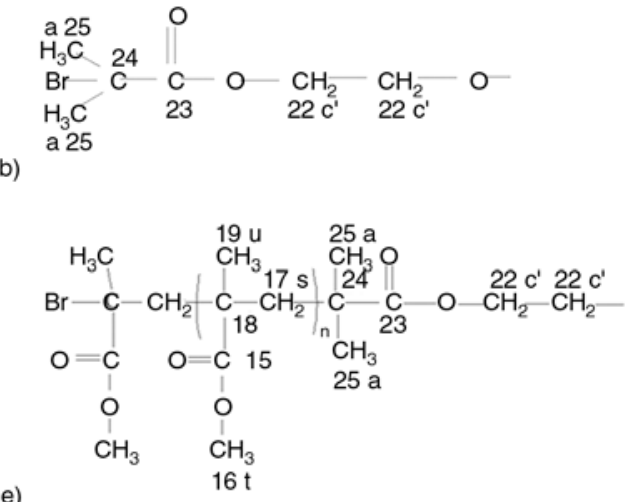

Figure 5. Chemical structure of (a) HMB, (b-d) MBP-PU-MBP and (c-e) PMMA- $b$-PU- $b$-PMMA tri-block copolymer, (CM4BrP6 sample) 
Table 1. ${ }^{1} \mathrm{H}$ NMR data of HMB, MBP-PU-MBP and PMMA- $b$-PU- $b$-PMMA copolymer, (CM4BrP6 sample)

\begin{tabular}{|c|c|c|c|}
\hline \multirow{2}{*}{$\begin{array}{c}\text { Type of nucleus } \\
{ }^{1} \mathbf{H}\end{array}$} & \multicolumn{2}{|c|}{ HMB } & \multicolumn{2}{c|}{ Chemical shift [ppm] } & - \\
\hline$g$ & 2.35 & - & - \\
\hline$c$ & $3.82-3.85$ & $1.88-1.92$ & $1.88-1.90$ \\
\hline$a$ & $1.94-1.95$ & $4.32-4.46$ & $9.32-4.37$ \\
\hline$c^{\prime}$ & $4.28-4.30$ & 9.50 & 7.30 \\
\hline$x$ & - & $7.32-7.35$ & 7.07 \\
\hline$l$ & - & $6.98-7.01$ & 3.78 \\
\hline$k$ & - & $3.78-3.82$ & 3,68 \\
\hline$d$ & - & $3.60-3.62$ & 3.31 \\
\hline$b^{\prime}$ & - & $3.24-3.32$ & $8.00-8.50$ \\
\hline$b$ & - & 8.50 & 4.04 \\
\hline$x^{\prime}$ & - & $4.04-4.06$ & $1.56-1.64$ \\
\hline$e$ & - & $1.56-1.68$ & 1.49 \\
\hline$f$ & - & $1.44-1.49$ & 3.56 \\
\hline$w$ & - & - & 2.07 \\
\hline$t$ & - & - & $0.74-1.28$ \\
\hline$s$ & - & & $-\mathrm{CH}_{3}$ of PMMA $(\mathrm{rr})$ \\
\hline$u$ & & & $-\mathrm{CH}_{3}$ of PMMA $(\mathrm{mr})$ \\
\hline & & & 0.91 \\
\hline
\end{tabular}

Table 2. ${ }^{13} \mathrm{C}$ NMR data of HMB, MBP-PU-MBP and PMMA- $b$-PU- $b$-PMMA copolymer, (CM4BrP6 sample)

\begin{tabular}{|c|c|c|c|}
\hline \multirow{2}{*}{$\begin{array}{c}\text { Type of nucleus } \\
{ }^{13} \mathrm{C}\end{array}$} & HMB & MBP-PU-MBP & PMMA-b-PU-b-PMMA, CM4BrP6 \\
\hline & \multicolumn{3}{|c|}{ Chemical shift [ppm] } \\
\hline 25 & $30.67-30.69$ & $30.10-30.22$ & 30.67 \\
\hline 24 & $55.36-55.85$ & $56.82-57.26$ & 48.50 \\
\hline 23 & $171.47-171.94$ & $170.65-170.84$ & $176.07-177.27$ \\
\hline 22 & $60.57-60.75$ & 61.65 & 63.81 \\
\hline 20 & $67.24-67.41$ & 67.28 & - \\
\hline 21 & & 40.00 & $38.93-39.93$ \\
\hline 13 & & $153.17-153.47$ & 162.20 \\
\hline 9 & & 135.22 & 135.66 \\
\hline 10 & & $118.17-121.08$ & 118.16 \\
\hline 11 & & $126.55-128.71$ & $125.65-128.73$ \\
\hline 12 & & $136.78-137.04$ & 137.06 \\
\hline 2 & & $69.61-69.66$ & 69.62 \\
\hline 4 & & 26.00 & 25.99 \\
\hline 5 & & 69.35 & 69.36 \\
\hline 6 & & 25.47 & 25.48 \\
\hline 7 & & 25.64 & 25.65 \\
\hline 8 & & $63.79-64.06$ & 63.81 \\
\hline 15 & & & 177.27 \\
\hline 16 & & & 51.62 \\
\hline 17 & & & 53.58 \\
\hline 18 & & & $43.81-44.18$ \\
\hline \multirow[t]{4}{*}{19} & & & $17.95-18.51$ \\
\hline & & & $-\mathrm{CH}_{3}$ of PMMA $(r r)$ \\
\hline & & & $-\mathrm{CH}_{3}$ of PMMA $(m r)$ \\
\hline & & & $-\mathrm{CH}_{3}$ of PMMA $(\mathrm{mm}) \quad 18.51$ \\
\hline
\end{tabular}

The tacticity of PMMA can be identified using the integration values of peaks at $0.75,0.91$, and $1.07-$ $1.28 \mathrm{ppm}$ which correspond to syndiotactic $(\mathrm{rr})$, atactic $(\mathrm{mr})$, and isotactic $(\mathrm{mm})$ PMMA, respec- tively [4]. The ratio among $\mathrm{rr}, \mathrm{mr}$, and $\mathrm{mm}$ in our study for CM4BrP6 is 53:34:13 which is similar to the reported tacticity ratio of PMMA prepared by ATRP [15]. 
The molar content of PMMA in the tri-block copolymers (4) can easily be found out by comparing molecular weights (obtained by GPC) of MBP-PUMBP and copolymers which are given in Table 3-6. It can also be found out using ${ }^{1} \mathrm{H}$ NMR technique (3) and the results are included in Table 3-6. The molar content of PMMA from GPC and ${ }^{1} \mathrm{H}$ NMR technique are comparatively similar.

\subsection{Kinetics and mechanism of the polymerization}

Reactions were carried out under homogeneous conditions. In this case we applied large excess of reducing agent in relation to the macroinitiator MBP-PU-MBP (8-fold; [Cu(0)]/[MBP-PU-MBP] = 8). An excess of reducing agent consumes the oxygen present in the system and, therefore, provides a deoxygenated environment for ATRP. The appropriate amount of reducing agent is crucial to achieve a controlled polymerization. The required amount of reducing agent is determined not only by the amount of $\mathrm{Cu}$ (II) complexes in the reaction system, but also by the amount of oxygen present in the vial. The volume of free space in a small glass vial was $\sim 4 \mathrm{~mL}$, which corresponds to $0.0375 \mathrm{mmol}$ of $\mathrm{O}_{2}$. Assuming that one $\mathrm{O}_{2}$ molecule oxidizes two $\mathrm{Cu}(0)$ molecules, this would correspond to the molar ratio of $[\mathrm{Cu}(0)]$ air/[MBP-PU-MBP] $=2 \cdot 0.0375 / 0.32=$

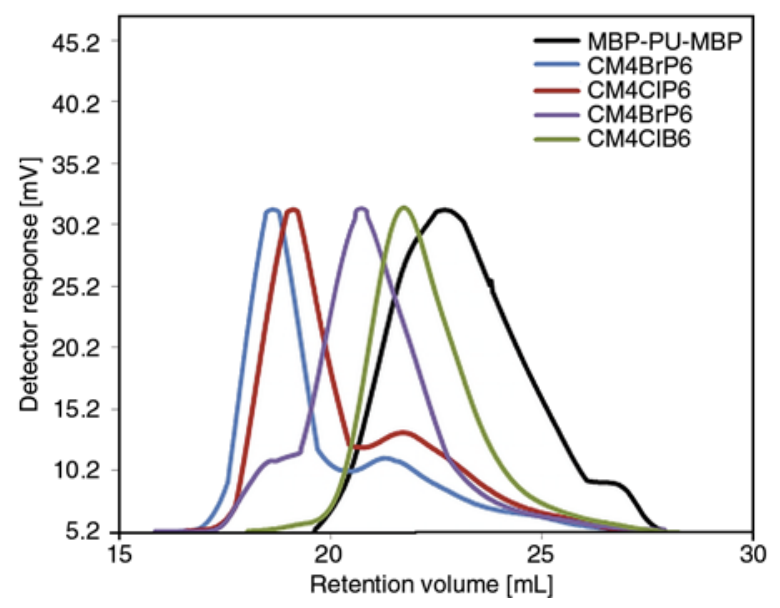

Figure 6. GPC eluograms of MBP-PU-MBP and copolymers CM4BrP6, CM4ClP6, CM4BrB6, CM4BrB6

0.23 , what is the amount of reducing agent needed to consume the oxygen present in the free space in a glass vial. Therefore, in this case amount of effective reducing agent is about $7.77([\mathrm{Cu}(0)]-$ $\left.[\mathrm{Cu}(0)]_{\mathrm{air}} /[\mathrm{MBP}-\mathrm{PU}-\mathrm{MBP}]\right)$ [3].

PMMA- $b$-PU- $b$-PMMA tri-block copolymers with narrow MWD were obtained, as confirmed by the GPC eluograms (Figure 6). The MWDs of the resulting copolymers are quite low in most cases.

To understand the mechanism of polymerization, effect of time on the polymerization of MMA was carried out and the results are presented in Table 3-6.

Table 3. Effect of time on ARGET ATRP of MMA using $\mathrm{CuBr}_{2} / \mathrm{PMDETA}$. Polymerization conditions: [MMA] $]_{0} /[\mathrm{MBP}-\mathrm{PU}-$ $\mathrm{MBP}]_{0} /\left[\mathrm{CuBr}_{2}\right]_{0} /[\mathrm{PMDETA}]_{0} /[\mathrm{Cu}(0)]=200 / 1 / 0.1 / 0.4 / 8$ in DMF

\begin{tabular}{|c|c|c|c|c|c|c|c|c|}
\hline Sample No. & $\begin{array}{c}\text { Time } \\
\text { [h] }\end{array}$ & $\begin{array}{c}\alpha \\
{[\%]}\end{array}$ & $\begin{array}{c}\boldsymbol{\beta}_{\mathrm{NMR}} \\
{[\%]}\end{array}$ & $\begin{array}{c}\beta_{\text {GPC }} \\
{[\%]}\end{array}$ & $\begin{array}{c}M_{\mathrm{n}, \mathrm{th}} \cdot 10^{-3} \\
{[\mathrm{~g} / \mathrm{mol}]}\end{array}$ & $\begin{array}{c}\mathrm{M}_{\mathrm{n}, \mathrm{GPC}} \cdot \mathbf{1 0}^{-3} \\
{[\mathrm{~g} / \mathrm{mol}]}\end{array}$ & $\begin{array}{c}\mathrm{M}_{\mathrm{w}, \mathrm{GPC}} \cdot \mathbf{1 0}^{-3} \\
{[\mathrm{~g} / \mathrm{mol}]}\end{array}$ & $\mathbf{M}_{\mathbf{w}} / \mathbf{M}_{\mathbf{n}}$ \\
\hline MBP-PU-MBP & 0 & 0.0 & 0.0 & 0.0 & 7.4 & 7.4 & 11.8 & 1.60 \\
\hline CM4BrP1 & 3 & 3.8 & 10.4 & 15.3 & 8.2 & 8.5 & 13.6 & 1.59 \\
\hline CM4BrP2 & 6 & 9.3 & 25.1 & 32.5 & 9.2 & 9.8 & 14.8 & 1.51 \\
\hline CM4BrP3 & 12 & 20.3 & 54.9 & 62.0 & 11.4 & 12.0 & 16.1 & 1.35 \\
\hline CM4BrP4 & 18 & 30.6 & 83.0 & 90.6 & 13.5 & 14.1 & 18.2 & 1.29 \\
\hline CM4BrP5 & 24 & 43.0 & 116.5 & 119.8 & 16.0 & 16.2 & 26.1 & 1.61 \\
\hline CM4BrP6 & 30 & 52.1 & 141.3 & 150.1 & 17.8 & 18.5 & 42.2 & 2.34 \\
\hline
\end{tabular}

Table 4. Effect of time on ARGET ATRP of MMA using $\mathrm{CuCl}_{2} / \mathrm{PMDETA}$. Polymerization conditions: [MMA $]_{0} /[\mathrm{MBP}-\mathrm{PU}-$ $\mathrm{MBP}]_{0} /\left[\mathrm{CuCl}_{2}\right]_{0} /[\mathrm{PMDETA}]_{0} /[\mathrm{Cu}(0)]=200 / 1 / 0.1 / 0.4 / 8$ in DMF

\begin{tabular}{|c|c|c|c|c|c|c|c|c|}
\hline Sample No. & $\begin{array}{c}\text { Time } \\
{[\mathrm{h}]}\end{array}$ & $\begin{array}{c}\alpha \\
{[\%]}\end{array}$ & $\begin{array}{c}\beta_{\text {NMR }} \\
{[\%]}\end{array}$ & $\begin{array}{c}\beta_{\mathrm{GPC}} \\
{[\%]}\end{array}$ & $\begin{array}{c}M_{n, t h} \cdot 10^{-3} \\
{[\mathrm{~g} / \mathrm{mol}]}\end{array}$ & $\begin{array}{c}\mathrm{M}_{\mathrm{n}, \mathrm{GPC}} \cdot 10^{-3} \\
{[\mathrm{~g} / \mathrm{mol}]}\end{array}$ & $\begin{array}{c}\mathrm{M}_{\mathrm{w}, \mathrm{GPC}} \cdot \mathbf{1 0}^{-3} \\
{[\mathrm{~g} / \mathrm{mol}]}\end{array}$ & $\mathbf{M}_{\mathbf{w}} / \mathbf{M}_{\mathrm{r}}$ \\
\hline MBP-PU-MBP & 0 & 0.0 & 0.0 & 0.0 & 7.4 & 7.4 & 11.8 & 1.60 \\
\hline CM4ClP1 & 3 & 3.8 & 10.4 & 16.2 & 8.2 & 8.6 & 13.6 & 1.58 \\
\hline CM4ClP2 & 6 & 9.3 & 25.1 & 29.9 & 9.2 & 9.6 & 15.4 & 1.60 \\
\hline CM4ClP3 & 12 & 16.3 & 44.2 & 53.7 & 10.6 & 11.4 & 16.6 & 1.47 \\
\hline CM4ClP4 & 18 & 27.5 & 74.7 & 79.6 & 12.9 & 13.3 & 28.5 & 2.15 \\
\hline CM4CIP5 & 24 & 35.4 & 96.0 & 106.1 & 14.5 & 15.2 & 26.6 & 1.75 \\
\hline CM4ClP6 & 30 & 46.4 & 125.8 & 135.6 & 16.7 & 17.4 & 38.8 & 2.23 \\
\hline
\end{tabular}


Table 5. Effect of time on ARGET ATRP of MMA using $\mathrm{CuBr}_{2} / \mathrm{Bpy}$. Polymerization conditions: [MMA $]_{0} /[\mathrm{MBP}-\mathrm{PU}-$ $\mathrm{MBP}]_{0} /\left[\mathrm{CuBr}_{2}\right]_{0} /[\mathrm{Bpy}]_{0} /[\mathrm{Cu}(0)]=200 / 1 / 0.1 / 0.4 / 8$ in DMF

\begin{tabular}{|c|c|c|c|c|c|c|c|c|}
\hline Sample No. & $\begin{array}{c}\text { Time } \\
{[\mathrm{h}]}\end{array}$ & $\begin{array}{c}\boldsymbol{\alpha} \\
{[\%]}\end{array}$ & $\begin{array}{c}\beta_{\mathrm{NMR}} \\
{[\%]}\end{array}$ & $\begin{array}{c}\boldsymbol{\beta}_{\mathrm{GPC}} \\
{[\%]}\end{array}$ & $\begin{array}{c}M_{\mathrm{n}, \mathrm{th}} \cdot 10^{-3} \\
{[\mathrm{~g} / \mathrm{mol}]}\end{array}$ & $\begin{array}{c}\mathrm{M}_{\mathrm{n}, \mathrm{GPC}} \cdot \mathbf{1 0}^{-3} \\
{[\mathrm{~g} / \mathrm{mol}]}\end{array}$ & $\begin{array}{c}\mathbf{M}_{\mathrm{w}, \mathrm{GPC}} \cdot 10^{-3} \\
{[\mathrm{~g} / \mathrm{mol}]}\end{array}$ & $\mathbf{M}_{\mathbf{w}} / \mathbf{M}_{\mathbf{n}}$ \\
\hline MBP-PU-MBP & 0 & 0.0 & 0.0 & 0.0 & 7.4 & 7.4 & 11.8 & 1.60 \\
\hline CM4BrB1 & 3 & 2.1 & 5.6 & 12.6 & 7.8 & 8.3 & 13.5 & 1.62 \\
\hline CM4BrB2 & 6 & 6.4 & 17.4 & 23.5 & 8.7 & 9.1 & 14.7 & 1.61 \\
\hline CM4BrB3 & 12 & 13.3 & 36.0 & 47.3 & 10.0 & 10.9 & 15.4 & 1.41 \\
\hline CM4BrB4 & 18 & 18.5 & 50.2 & 66.2 & 11.1 & 12.3 & 16.8 & 1.37 \\
\hline CM4BrB5 & 24 & 27.5 & 74.7 & 85.1 & 12.9 & 13.7 & 25.6 & 1.87 \\
\hline CM4BrB6 & 30 & 35.9 & 97.3 & 106.0 & 14.6 & 15.2 & 29.0 & 1.91 \\
\hline
\end{tabular}

Table 6. Effect of time on ARGET ATRP of MMA using $\mathrm{CuCl}_{2} / \mathrm{Bpy}$. Polymerization conditions: [MMA $]_{0} /[\mathrm{MBP}-\mathrm{PU}-$ $\mathrm{MBP}]_{0} /\left[\mathrm{CuCl}_{2}\right]_{0} /[\mathrm{Bpy}]_{0} /[\mathrm{Cu}(0)]=200 / 1 / 0.1 / 0.4 / 8$ in DMF

\begin{tabular}{|c|c|c|c|c|c|c|c|c|}
\hline Sample No. & $\begin{array}{c}\text { Time } \\
{[\mathrm{h}]}\end{array}$ & $\begin{array}{c}\boldsymbol{\alpha} \\
{[\%]}\end{array}$ & $\begin{array}{c}\boldsymbol{\beta}_{\mathrm{NMR}} \\
{[\%]}\end{array}$ & $\begin{array}{c}\beta_{\mathrm{GPC}} \\
{[\%]}\end{array}$ & $\begin{array}{c}M_{\mathrm{n}, \mathrm{th}} \cdot 10^{-3} \\
{[\mathrm{~g} / \mathrm{mol}]}\end{array}$ & $\begin{array}{c}\mathrm{M}_{\mathrm{n}, \mathrm{GPC}} \cdot \mathbf{1 0}^{-3} \\
{[\mathrm{~g} / \mathrm{mol}]}\end{array}$ & $\begin{array}{c}\mathrm{M}_{\mathrm{w}, \mathrm{GPC}} \cdot \mathbf{1 0}^{-3} \\
{[\mathrm{~g} / \mathrm{mol}]}\end{array}$ & $\mathbf{M}_{\mathbf{w}} / \mathbf{M}_{\mathbf{n}}$ \\
\hline MBP-PU-MBP & 0 & 0.0 & 0.0 & 0.0 & 7.4 & 7.4 & 11.8 & 1.60 \\
\hline CM4ClB1 & 3 & 2.1 & 5.7 & 10.2 & 7.8 & 8.1 & 12.5 & 1.54 \\
\hline CM4ClB2 & 6 & 3.3 & 9.0 & 16.7 & 8.0 & 8.6 & 13.6 & 1.58 \\
\hline CM4ClB3 & 12 & 9.7 & 26.2 & 37.4 & 9.3 & 10.2 & 15.1 & 1.49 \\
\hline CM4ClB4 & 18 & 17.6 & 47.7 & 53.7 & 10.9 & 11.4 & 15.5 & 1.37 \\
\hline CM4ClB5 & 24 & 21.5 & 58.3 & 66.8 & 11.7 & 12.3 & 16.5 & 1.37 \\
\hline CM4ClB6 & 30 & 27.1 & 73.6 & 82.3 & 12.8 & 13.5 & 17.7 & 1.32 \\
\hline
\end{tabular}
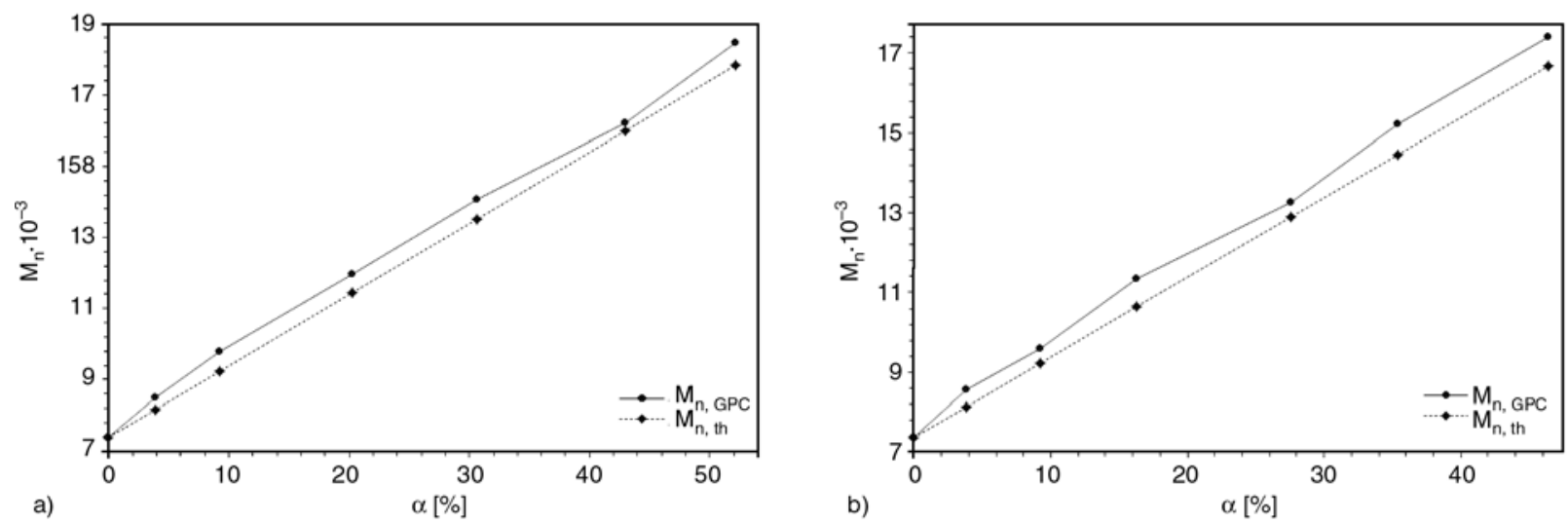

Figure 7. Comparison of $M_{\mathrm{n} \text {, th }}$ and $M_{\mathrm{n}, \mathrm{GPC}}$ as a function of monomer conversion plots for the polymerization of MMA at using MBP-PU-MBP/CuBr $2 / \mathrm{PMDETA}$ (a) and MBP-PU-MBP/CuCl $2 / \mathrm{PMDETA}$ (b) initiating system

As the polymerization time increases, there is an increase in conversion and $M_{\mathrm{n}, \mathrm{th}}$. Here the concentration of $\mathrm{Br}$ in MBP-PU-MBP was calculated using molecular weight of MBP-PU-MBP obtained through GPC $\left(2 \cdot 1.18 / 7400=3.2 \cdot 10^{-4} \mathrm{~mol} \mathrm{Br}\right)$.

Figures $7 \mathrm{a}$ and $7 \mathrm{~b}$ shows $M_{\mathrm{n}}$ versus monomer conversion plots for the polymerization of MMA, whereas Figure 8 present $\ln \left([\mathrm{M}]_{0} /[\mathrm{M}]\right)$-vs-time plots for the polymerization of MMA, where $[\mathrm{M}]_{0}$ and $[\mathrm{M}]$ represent the initial monomer concentration and the monomer concentration at time $t$, respectively. The straight line obtained in semi-logarithmic plots of $\ln \left([\mathrm{M}]_{0} /[\mathrm{M}]\right)$ versus time shows that the concentration of propagating radical is constant dur-

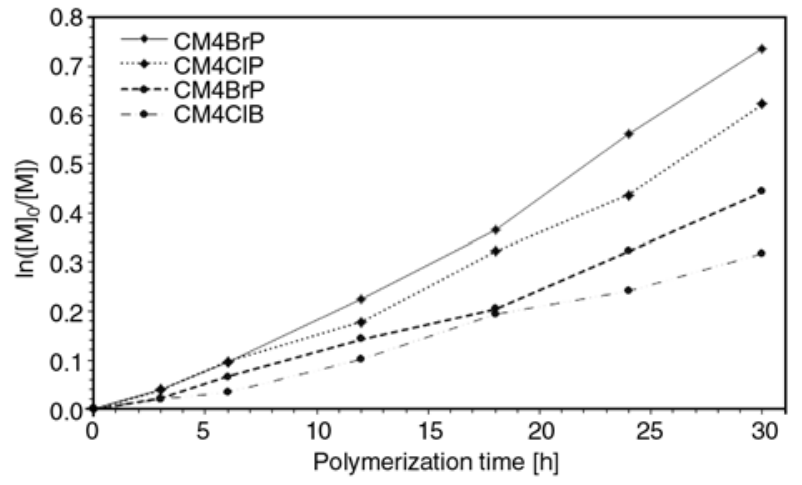

Figure 8. Comparison of $\ln \left([\mathrm{M}]_{0} /[\mathrm{M}]\right)$-polymerization time plots for the polymerization of MMA at using $\mathrm{CuBr}_{2}$ /PMDETA (CM4BrP), $\mathrm{CuCl}_{2} / \mathrm{PMDETA}$ (CM4ClP), $\mathrm{CuBr}_{2}$ /Bpy (CM4BrB) and $\mathrm{CuCl}_{2} /$ Bpy (CM4ClB) catalyst complex 
ing the studied period of time. In all cases (Table 36) $M_{\mathrm{n}, \mathrm{GPC}}$, increases with increasing monomer conversion which is a clear evidence for the 'living' nature of the initiating systems (and its values found to be comparable). Moreover MWD of the tri-block copolymers remains narrow in the polymers from higher polymerization time (Table 3-6). After $30 \mathrm{~h}$, maximum conversion obtained for the MBP-PU-MBP/CuBr 2 /PMDETA initiating system was $52.1 \%\left(M_{\mathrm{n}}=18500 \mathrm{~g} / \mathrm{mol}\right.$, Table $3, \mathrm{CM} 4 \mathrm{BrP}$ sample). However copolymer with MWD amount 2.34 was received. Therefore, to study the effect of nature of the catalyst, $\mathrm{CuCl}_{2}$ was used instead of $\mathrm{CuBr}_{2}$ for the polymerization of MMA (Table 4). Similarly to the previous system, MBP-PU-MBP/ $\mathrm{CuCl}_{2} / \mathrm{PMDETA}$ initiating system also shows 'livingness' during the formation of the tri-block copolymers. After $30 \mathrm{~h}$, the reaction reached $46.4 \%$ conversion and $M_{\mathrm{n}}$ was $17400 \mathrm{~g} / \mathrm{mol}$ (Table 4, CM4ClP sample). The conversion in $\mathrm{CuCl}_{2}$ system is lower than the $\mathrm{CuBr}_{2}$ system, but based on the MWD values former system is more controlled than the latter system.

As $\mathrm{R}-\mathrm{Cl}$ bond is stronger than $\mathrm{R}-\mathrm{Br}$ bond, $\mathrm{CuCl}_{2}$ acts as a good deactivator of the radical generated from MBP-PU-MBP than $\mathrm{CuBr}_{2}$ and as a result conversion in $\mathrm{CuCl}_{2}$ system was lower than the $\mathrm{CuBr}_{2}$ system. However 'living' nature of both the initiating systems was confirmed by linear increase of $M_{\mathrm{n}}$ with conversion plots. Moreover 'living' nature was further supported by the good agreement between $M_{\mathrm{n}, \mathrm{th}}$ and $M_{\mathrm{n}, \mathrm{GPC}}$ values [16].

To study the effect of nature of the complexing agent, Bpy was used instead of PMDETA for the ARGET ATRP of MMA and the results are presented in Table 5 and 6. The monomer conversion in Bpy systems is lower than the PMDETA systems but based on the MWD values former system is more controlled than the latter system. The higher monomer conversion in PMDETA systems follows directly from the fact that catalyst activity depends on type of ligand [17] and their activation rate constants - PMDETA has activation rate constant higher by an order of magnitude in relation to bpy [18]. There is a little lack of linearity especially in the $\ln \left([\mathrm{M}]_{0} /[\mathrm{M}]\right)$-vs-time plot (Figure 8 ), this might be due to the lack of inefficient deactivation by $\mathrm{CuBr}_{2} /$ Bpy and $\mathrm{CuCl}_{2} / \mathrm{Bpy}$ initiating system complex, which leads to the irreversible radical-radical termination as side reactions.
One of the drawbacks of ARGET is that ligand must be added to metal at 3 to 10 times molar excess in order to achieve a controlled polymerization. The excess ligand helps to maintain the catalyst complex and protect it from destabilizing side reactions. These side reactions vary depending on reaction conditions, but generally include monomer complexation to catalyst, and destabilization or complexation of catalyst to Lewis acids formed from the reduction mechanism [5].

It is interesting to note that when $-\mathrm{CH}_{2} \mathrm{Br}$ terminated polyurethane was used in our earlier investigation [13], $M_{\mathrm{n}, \mathrm{GPC}}$ and $M_{\mathrm{n} \text {,th }}$ values were nowhere near, but in the present case it is comparable. Dibromo PU macroinitiator contains primary alkyl halide groups, show slow activation rate (and fast deactivation rate) are compared it the high activation (and slow deactivation) of the propagating PMMA chain end [4]. This result shows that 2methyl-2-bromopropionate terminated $\mathrm{PU}$ is better macroinitiator than $-\mathrm{CH}_{2} \mathrm{Br}$ terminated $\mathrm{PU}$, because it can generated the tertiary radical, which is more stable than the previously reported primary radical [7]. Another important fact is that the ATRP of MMA is itself difficult to control. Though the initiation is slow, the controlled polymerization of the present initiating system and the formation block copolymers can be confirmed by $\ln \left([\mathrm{M}]_{0} /[\mathrm{M}]\right)$-polymerization time, $M_{\mathrm{n}}$-monomer conversion and spectral results.

\subsection{Thermal studies}

Thermal stability of MBP-PU-MBP and copolymers (CM4BrP6, CM4CIP6, CM4BrB6, CM4BrB6) was also studied using TGA and the results are presented in Figure 9 and Table 7.

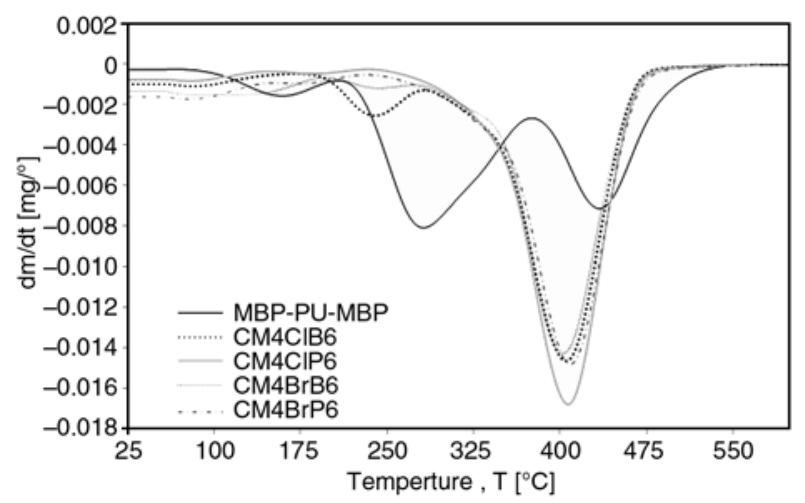

Figure 9. DTG thermograms for MBP-PU-MBP and copolymers CM4BrP6, CM4ClP6, CM4BrB6, CM4BrB6 
Table 7. Thermal stability of MBP-PU-MBP and copolymers CM4BrP6, CM4ClP6, CM4BrB6, CM4BrB6

\begin{tabular}{|c|c|c|c|c|c|c|c|}
\hline Sample No. & \multicolumn{2}{|c|}{ I stage degradation } & \multicolumn{2}{|c|}{ II stage degradation } & \multicolumn{2}{|c|}{ III stage degradation } & \multirow{2}{*}{$\begin{array}{c}\text { Sumary } \\
\text { mass loss } \\
{[\%]}\end{array}$} \\
\hline & $\begin{array}{c}\text { Mass loss } \\
{[\%]}\end{array}$ & $\begin{array}{c}\mathbf{T} \\
{\left[{ }^{\circ} \mathbf{C}\right]}\end{array}$ & $\begin{array}{c}\text { Mass loss } \\
{[\%]}\end{array}$ & $\begin{array}{c}\mathbf{T} \\
{\left[{ }^{\circ} \mathbf{C}\right]}\end{array}$ & $\begin{array}{c}\text { Mass los } \\
{[\%]}\end{array}$ & $\begin{array}{c}\mathrm{T} \\
{\left[{ }^{\circ} \mathrm{C}\right]}\end{array}$ & \\
\hline MBP-PU-MBP & 8.16 & 162 & 48.54 & 282 & 39.21 & 438 & 95.91 \\
\hline CM4BrP6 & - & - & - & - & 95.02 & 413 & 95.02 \\
\hline CM4ClP6 & - & - & - & - & 95.29 & 409 & 95.29 \\
\hline CM4BrB & - & - & - & - & 93.55 & 404 & 93.55 \\
\hline CM4ClB & - & - & 16.15 & 240 & 78.12 & 408 & 94.27 \\
\hline
\end{tabular}

MBP-PU-MBP undergoes three-stage decomposition, while the overall thermal stability of tri-block copolymers is higher than the MBP-PU-MBP. Thermal degradation of the polymers CM4BrP6, CM4C1P6 and CM4BrB6 occurred around 413, 409 and $404^{\circ} \mathrm{C}$ respectively which shows the presence random scission only. Whereas, CM4ClB6 copolymer undergoes two-stage decomposition, first is due to the decomposition of the NHCOO groups $\left(240^{\circ} \mathrm{C}\right)$ and another is due to the decomposition of PTMG blocks $\left(408^{\circ} \mathrm{C}\right)$, it is probably due to the low content of PMMA segments (molar content of PMMA at about $74-82 \%$ ). This result is a further indication of the absence of abnormal linkages therefore confirming the high regioselectivity and absence of unwanted irreversible termination or transfer reactions.

\subsection{Studies of surface properties of the tri-block copolymer coatings}

Images of tri-block copolymer coatings and the level of them roughness parameters vary from contains of hard phase, which comes from MMA segments (Figure 10).

Surface images of CM4BrP6 (Figure 10a), CM4ClP6 (Figure 10b) and CM4BrB6 (Figure 10c) copolymer samples with molar content of PMMA at about 141-150, 126-137 and 97-106\% exhibit higher values of the roughness parameters $\left(R_{\mathrm{a}}=0.30\right.$ $\left.0.45 \mu \mathrm{m}, R_{\mathrm{Z}}=1.55-2.39 \mu \mathrm{m}\right)$ in relation to $\mathrm{CM} 4 \mathrm{ClB} 6$
(Figure 10d) sample obtained at the lowest molar content of PMMA $74-82 \%\left(R_{\mathrm{a}}=0.20 \mu \mathrm{m}, R_{\mathrm{z}}=\right.$ $1.14 \mu \mathrm{m})$.

The shape of the surface (roughness and physical form) copolymer coatings justifies the designation of $\Theta$ and SFE.

Table 8 provides the values of $\Theta$ as found and also components of SFE calculated on the basis of those angles in accordance with the van Oss-Good method, for coatings obtained from the studied tri-block copolymers. One can see a decrease in $\Theta$ values for both polar liquids (water and formamide) and nonpolar liquid (diiodomethan), together with lower content MMA segments. The presented data show that MMA segments, when incorporated into hard segments of copolymers, are responsible for considerable reduction in SFE of the coatings obtained from those copolymers. The findings from the van Oss-Good method bring us to the conclusion that the basic impact on the value of $\gamma_{\mathrm{S}}$ comes from the $\gamma_{\mathrm{S}}{ }^{\mathrm{LW}}$ component of long-range interactions. However, the values of acid-base interactions $\gamma_{\mathrm{S}}{ }^{\mathrm{AB}}$ cannot be evaluated precisely and these should be estimated as $0.30-0.56 \mathrm{~mJ} / \mathrm{m}^{2}$.

\section{Conclusions}

Polyurethane-based macroinitiator, MBP-PU-MBP has been used to synthesize PMMA- $b$-PU- $b$-PMMA tri-block copolymers through ARGET ATRP in the presence of limited amounts of air. Excess reducing

Table 8. Experimental values of contact angles, parameters of FSE as calculated by van Oss-Good method and roughness parameters for tri-block copolymer coatings

\begin{tabular}{|c|c|c|c|c|c|c|c|c|c|c|c|c|c|}
\hline \multirow{2}{*}{$\begin{array}{c}\text { Sample } \\
\text { No. }\end{array}$} & \multicolumn{6}{|c|}{$\begin{array}{c}\text { Experimental values of contact angles } \Theta \\
{\left[{ }^{\circ}\right]} \\
\text { Model measuring fluids }\end{array}$} & \multicolumn{5}{|c|}{$\begin{array}{c}\text { Parameters of FSE } \\
{\left[\mathrm{mJ} / \mathbf{m}^{2}\right]}\end{array}$} & \multicolumn{2}{|c|}{$\begin{array}{c}\text { Roughness } \\
\text { parameters } \\
{[\mu \mathrm{m}]}\end{array}$} \\
\hline & $\mathrm{CH}_{2} \mathrm{I}_{2}$ & \begin{tabular}{|l|} 
Standard \\
deviation
\end{tabular} & Formamide & \begin{tabular}{|l|} 
Standard \\
deviation
\end{tabular} & Water & $\begin{array}{l}\text { Standard } \\
\text { deviation }\end{array}$ & $\gamma \mathrm{s}^{\mathrm{LW}}$ & $\gamma_{\mathrm{s}^{-}}$ & $\gamma_{s^{+}}^{+}$ & $\gamma_{\mathrm{s}}{ }^{\mathrm{AB}}$ & $\gamma_{\mathrm{s}}$ & $\mathbf{R}_{\mathbf{a}}$ & $\mathbf{R}_{\mathbf{z}}$ \\
\hline CM4BrP6 & 36.10 & 1.29 & 63.56 & 1.96 & 86.28 & 1.53 & 40.90 & 2.16 & 0.01 & 0.30 & 41.2 & 0.45 & 2.39 \\
\hline CM4ClP6 & 35.35 & 1.03 & 61.78 & 1.61 & 84.20 & 1.70 & 41.68 & 2.75 & 0.01 & 0.32 & 42.0 & 0.40 & 1.94 \\
\hline CM4BrB6 & 34.10 & 1.21 & 59.62 & 1.20 & 81.68 & 1.73 & 42.61 & 3.67 & 0.01 & 0.32 & 42.9 & 0.30 & 1.55 \\
\hline CM4ClB6 & 33.18 & 0.58 & 56.93 & 1.52 & 80.65 & 1.36 & 42.94 & 4.05 & 0.02 & 0.56 & 43.5 & 0.20 & 1.14 \\
\hline
\end{tabular}




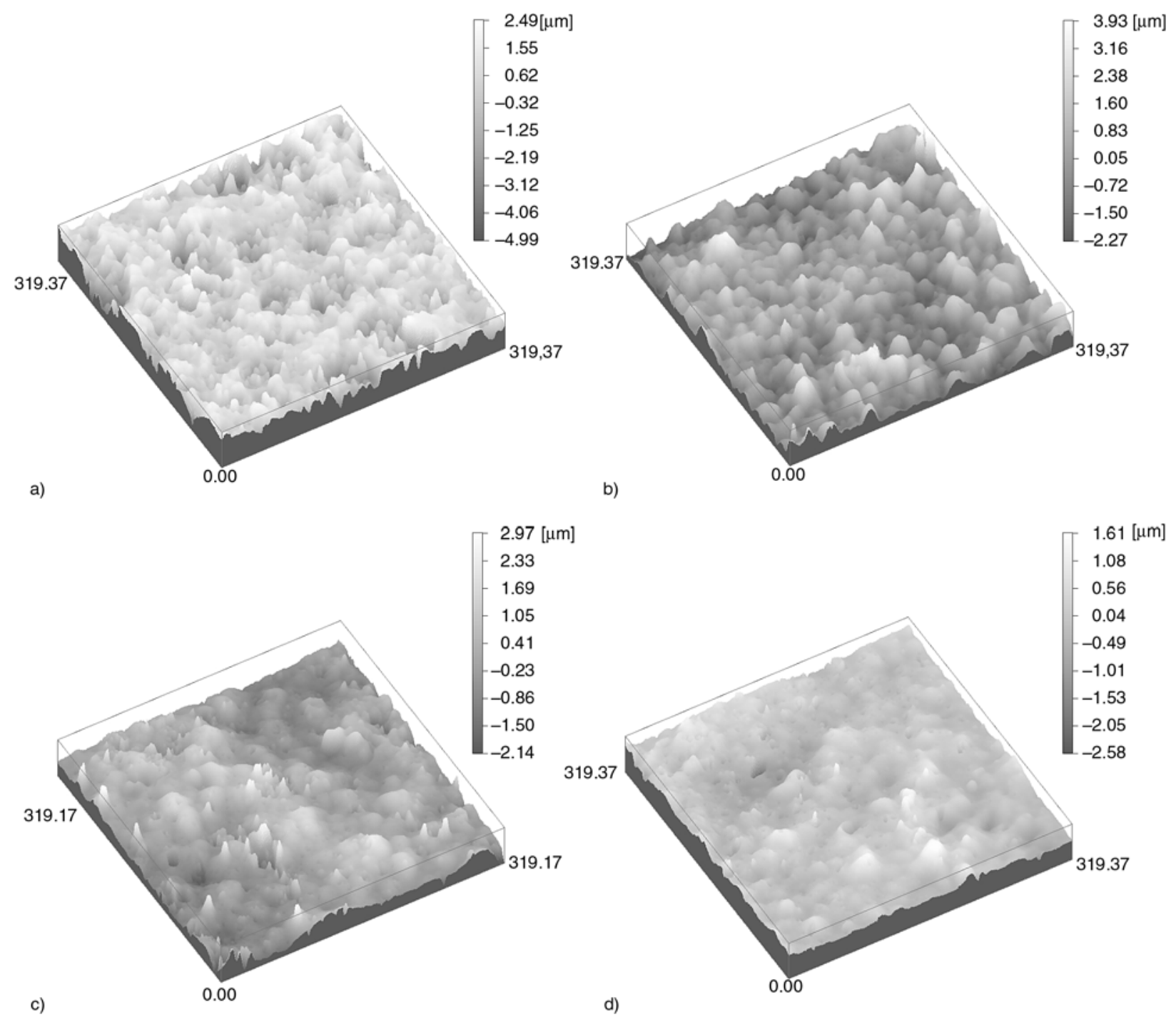

Figure 10. Pictures of the surface of CM4BrP6 (a), CM4ClP6 (b), CM4BrB6 (c) and CM4ClB6 (d) tri-block copolymers, taken for the objects $320 \times 320 \mu \mathrm{m}$ with magnification $50 \times$

agent slightly accelerates ATRP but does not interfere with the controlled growth. This approach virtually eliminates any requirement for the deoxygenation of reaction mixtures or the use of a vacuum line or Schlenk line. The linear increase of monomer conversion and $\ln \left([\mathrm{M}]_{0} /[\mathrm{M}]\right)$ during the increase of polymerization time confirms that the formation of tri-block copolymers was through controlled radical polymerization. Moreover, the linear increase of number average molecular weight with increase of monomer conversion is also the clear evidence to prove the controlled radical polymerization mechanism. $M_{\mathrm{n} \text {,th }}$ of the tri-block copolymers was found to be more or less similar to $M_{\mathrm{n}, \mathrm{GPC}}$. In contrast to $-\mathrm{CH}_{2} \mathrm{Br}$ terminated $\mathrm{PU}$, tertiary bromine-terminated PU produced PMMA- $b$-PU- $b$-PMMA tri- block copolymers with narrow MWD values. The molar percentage of PMMA calculated through ${ }^{1} \mathrm{H}$ NMR is matching with GPC results. The results from ${ }^{1} \mathrm{H}$ and ${ }^{13} \mathrm{C}$ NMR spectral and thermal studies support the formation of HMB, MBP-PU-MBP and PMMA-b-PU-b-PMMA tri-block copolymers. The studies of surface properties of tri-block copolymer coatings confirmed the presence of MMA segments.

Structures of PMMA- $b$-PU- $b$-PMMA tri-block copolymers are already common used as biomedical materials [19] as well as biodegradable scaffolds in the tissue engineering of skeletal muscles [20]. Moreover they are finding application as adhesives, emulsifiers, modifiers of surface properties and polymer blend compatibilizers [19]. 


\section{Acknowledgements}

The scientific work is co-financed by resources of European Union, in frames of European Social Fund, and project Podkarpacki scholarship fund for doctoral students realized by Podkarpackie Province - Marshall office of the Podkarpacki Province in Rzeszów in frames of Operating Programme the Human Capital in years 2007-2013.

\section{References}

[1] Matyjaszewski K., Dong H., Jakubowski W., Pietrasik J., Kusumo A.: Grafting from surfaces for 'Everyone': ARGET ATRP in the presence of air. Langmuir, 23, 4528-4531 (2007). DOI: $10.1021 / 1 \mathrm{a} 063402 \mathrm{e}$

[2] Jakubowski W., Min K., Matyjaszewski K.: Activators regenerated by electron transfer for atom transfer radical polymerization of styrene. Macromolecules, 39, 39-45 (2006). DOI: $10.1021 / \mathrm{ma} 0522716$

[3] Dong H., Matyjaszewski K.: ARGET ATRP of 2(dimethylamino)ethyl methacrylate as an intrinsic reducing agent. Macromolecules, 41, 6868-6870 (2008). DOI: $10.1021 / \mathrm{ma} 8017553$

[4] Tharanikkarasu K., Verma H., Jang W., Lee S. K., Seo J., Baek S., Han H.: Novel poly(methyl methacrylate)block-polyurethane-block-poly(methyl methacrylate) tri-block copolymers through atom transfer radical polymerization. Journal of Applied Polymer Science, 108, 1538-1544 (2008).

DOI: $10.1002 / \mathrm{app} .27642$

[5] Tharanikkarasu K., Kim B. K.: Modification of aqueous polyurethane dispersions via tetraphenylethane iniferters. Journal of Applied Polymer Science, 73, 2993-3000 (1999).

DOI: $10.1002 /(\mathrm{SICI}) 1097-4628(19990929) 73: 14<2993$ $\because$ AID-APP24>3.0.CO;2-B

[6] Verma H., Kannan T.: Novel telechelic 2-methyl-2-bromopropionate terminated polyurethane macroinitiator for the synthesis of ABA type tri-block copolymers through atom transfer radical polymerization of methyl methacrylate. Polymer Journal, 40, 867-874 (2008). DOI: 10.1295/polymj.PJ2007236

[7] Nayak S., Verma H., Kannan T.: Synthesis and characterization of amphiphilic and hydrophobic ABA-type tri-block copolymers using telechelic polyurethane as atom transfer radical polymerization macroinitiator. Colloid and Polymer Science, 288, 181-188 (2010). DOI: $10.1007 / \mathrm{s} 00396-009-2149-2$

[8] Yin Z., Koulic C., Pagnoulle C., Jérôme R.: Reactive blending of functional PS and PMMA: Interfacial behavior of in situ formed graft copolymers. Macromolecules, 34, 5132-5139 (2001).

DOI: $10.1021 / \mathrm{ma} 001798+$

[9] Viala S., Antonietti M., Tauer K., Bremser W.: Structural control in radical polymerization with 1,1 diphenylethylene: 2. Behavior of MMA-DPE copolymer in radical polymerization. Polymer, 44, 1339-1351 (2003). DOI: 10.1016/S0032-3861(03)00004-1
[10] Król B., Król P., Pikus S., Chmielarz P., Skrzypiec K.: Synthesis and characterisation of coating polyurethane cationomers containing fluorine built-in hard urethane segments. Colloid and Polymer Science, 288, 12551269 (2010).

DOI: $10.1007 / \mathrm{s} 00396-010-2244-4$

[11] Sarbu T., Lin K-Y., Spanswick J., Gil R. R., Siegwart D. J., Matyjaszewski K.: Synthesis of hydroxytelechelic poly(methyl acrylate) and polystyrene by atom transfer radical coupling. Macromolecules, 34, 9694-9700 (2004).

DOI: $10.1021 / \mathrm{ma0} 484375$

[12] Koulic C., Yin Z., Pagnoulle C., Gilbert B., Jérôme R.: Premade versus in situ formed compatibilizer at the PS/PMMA interface: Contribution of the Raman confocal microscopy to the fracture analysis. Polymer, 42, 2947-2957 (2001).

DOI: $10.1016 / \mathrm{S} 0032-3861(00) 00553-\mathrm{X}$

[13] Król P., Chmielarz P.: Controlled radical polymerization as the method for modification of polyurethanes by vinyl polymers. in 'Modern Polymeric Materials for Environmental Applications $4^{\text {th }}$ International Seminar, Kraków, Poland' 169-174 (2010).

[14] Lapprand A., Boisson F., Delolme F., Méchin F., Pascault J-P.: Reactivity of isocyanates with urethanes: Conditions for allophanate formation. Polymer Degradation and Stability, 90, 363-373 (2005).

DOI: $10.1016 /$ j.polymdegradstab.2005.01.045

[15] de la Fuente J. L., Fernández-Garcia M., FernándezSanz M., Madruga E. L.: Sequence distribution and stereoregularity of methyl methacrylate and butyl acrylate statistical copolymers synthesized by atom transfer radical polymerization. Macromolecules, 34, 58335837 (2001). DOI: $10.1021 / \mathrm{ma} 010428 \mathrm{y}$

[16] Verma H., Kannan T.: Synthesis of tri-block copolymers through reverse atom transfer radical polymerization of methyl methacrylate using polyurethane macroiniferter. Express Polymer Letters, 2, 579-588 (2008). DOI: 10.3144 /expresspolymlett.2008.70

[17] di Lena F., Matyjaszewski K.: Transition metal catalysts for controlled radical polymerization. Progress in Polymer Science, 35, 959-1021 (2010).

DOI: 10.1016/j.progpolymsci.2010.05.001

[18] Tsarevsky N. V., Matyjaszewski K.: 'Green' atom transfer radical polymerization: From process design to preparation of well-defined environmentally friendly polymeric materials. Chemical Reviews, 107, 2270-2299 (2007).

DOI: $10.1021 / \mathrm{cr} 050947 \mathrm{p}$

[19] Król P., Chmielarz P.: Controlled radical polymerization (CRP) methods in the synthesis of polyurethane copolymers (in Polish). Polimery, 56, 530-540 (2011).

[20] Sharifpoor S., Labow R. S., Santerre J. P.: Synthesis and characterization of degradable polar hydrophobic ionic polyurethane scaffolds for vascular tissue engineering applications. Biomacromolecules, 10, 27292739 (2009).

DOI: $10.1021 / \mathrm{bm} 9004194$ 